\title{
APPLICATION OF TECHNICAL MEASURES AND SOFTWARE IN CONSTRUCTING PHOTOREALISTIC 3D MODELS OF HISTORICAL BUILDING USING GROUND-BASED AND AERIAL (UAV) DIGITAL IMAGES
}

\author{
Aleksander Zarnowski ${ }^{1}$, Anna Banaszek ${ }^{2}$, Sebastian Banaszek ${ }^{3}$ \\ 1) Department of Geoinformatics, Koszalin University of Technology, Koszalin, Poland \\ 2) Department of Real Estate Resources, University of Warmia and Mazury, \\ Olsztyn, Poland \\ 3) Dron House S.A., Warsaw, Poland
}

\begin{abstract}
Preparing digital documentation of historical buildings is a form of protecting cultural heritage. Recently there have been several intensive studies using non-metric digital images to construct realistic $3 D$ models of historical buildings. Increasingly often, non-metric digital images are obtained with unmanned aerial vehicles (UAV). Technologies and methods of UAV flights are quite different from traditional photogrammetric approaches. The lack of technical guidelines for using drones inhibits the process of implementing new methods of data acquisition.

This paper presents the results of experiments in the use of digital images in the construction of photo-realistic 3D model of a historical building (Raphaelsohns' Sawmill in Olsztyn). The aim of the study at the first stage was to determine the meteorological and technical conditions for the acquisition of aerial and ground-based photographs. At the next stage, the technology of $3 D$ modelling was developed using only ground-based or only aerial non-metric digital images. At the last stage of the study, an experiment was conducted to assess the possibility of $3 D$ modelling with the comprehensive use of aerial (UAV) and ground-based digital photographs in terms of their labour intensity and precision of development. Data integration and automatic photo-realistic $3 D$ construction of the models was done with Pix4Dmapper and Agisoft PhotoScan software Analyses have shown that when certain parameters established in an experiment are kept, the process of developing the stock-taking documentation for a historical building moves from the standards of analogue to digital technology with considerably reduced cost.
\end{abstract}

Keywords: $3 D$ modelling, digital image, UAV, Pix4Dmapper, Agisoft PhotoScan 


\section{Introduction}

Nowadays 3D data are a critical component to permanently record the form of important objects and sites. Virtualisation of historical buildings is the foundation for various measures aimed at protecting national heritage, such as documentation, digital preservation and conservation, monitoring, simulation of aging and deterioration, web-based geographic systems, virtual tours, multimedia museum exhibitions and so on (Remondino, 2011; Bruno et al., 2010).

All of these measures require pre-generation of a 3D model of a selected building. Automatic acquisition of a 3D model from digital images has been discussed in the literature for years (Koch et al., 1998; Pollefeys et al., 1999; Hirschmuller, 2008; Pierrot-Deseilligny et al., 2011) Automatic alignment of images and the construction of a full, detailed, precise and realistic 3D model from images is still a difficult task, especially when the images used are not calibrated, and requires large experience and knowledge.

The latest development in using non-metric digital images to construct realistic 3D models of historical buildings are promising. This has been affected by expansion of the possibility of automating image data processing with specialist photogrammetric modelling programs. Utilizing open-source software such as Meshlab, freeware such as 123D Catch and licensed software such as Agisoft PhotoScan Pro, it is now costeffective to utilize photogrammetry in any project (Preuss, 2014; Diara, 2013). Nonmetric images are increasingly often acquired using unmanned aerial vehicles (UAV). For example, they are used in creating virtual and photo-realistic 3D models, both of individual buildings (Pueschel et al., 2008; Uysal et al., 2013; Boroń et al., 2009) and whole cultural landscapes (Brumana et al., 2011). Some research work at archaeological sites has also been designed and performed as well (Sauerbier \& Eisenbeiss, 2010; Bykov et al., 2012).

This paper presents the results of experiments in utilising digital images to construct a photorealistic 3D model of a historical building. It discusses the current possibilities of the automated processing of aerial (acquired by UAV) and groundbased images with Pix4Dmapper and Agisoft PhotoScan software.

\section{Research experiment description}

According to the technical guidelines K-2.7 Principles of taking aerial photographs, the process of preparation and performing a flight for photogrammetry and teledetection should include the following stages:

- selecting the photo-aerial equipment,

- specifying the meteorological conditions of the flight mission,

- preparing a flight design and establishing navigation tolerance,

- designing and signalling of the ground control points,

- the flight,

- examination of the photographic and photogrammetric quality of the images.

The aim of the first stage of the study was to develop the technical task in accordance with the principles mentioned above in order to acquire aerial (UAV) and ground-based digital images of good geometric and radiometric quality. The next stage involved developing the optimum technology for the 3D modelling of a historical building (with the Raphaelsohns' Sawmill in Olsztyn as an example) using only ground-based or aerial non-metric digital images. In the last stage, an 
experiment was conducted to assess the possibility of $3 \mathrm{D}$ modelling with the comprehensive use of non-metric aerial and ground-based non-metric digital images in terms of its labour intensity and precision of elaboration.

The following equipment and software were used in order to assess the possibility of using a block of images acquired with a non-metric camera to generate a 3D model of a historical building:

1. Unmanned aerial vehicle: DJI Inspire 1 with an FC350 camera.

2. Compact class digital camera: Panasonic DMC-FT1.

3. Zoom class digital camera: Panasonic DMC-FZ30.

4. Graphic workstation 1: Computer: HP 640 Workstation (CPU: Intel Xeon CPU E5-2620 v3; RAM: 48 GB 2,4 GHz; Graphic card: NVIDIA Quadro K2200, 4 GB; HDD: ATA ST1000DM003-1ER1 SCASI Disk Device).

5. Graphic workstation 2: Computer: HP 640 Workstation (CPU: 2 x Intel Xeon CPU E5-2620 v3; RAM: 64 GB 2,4 GHz; Graphic card: NVIDIA Quadro K2200, 4 GB; HDD: ATA Hitahi HDS72101 SCASI Disk Device).

6. Software: Agisoft PhotoScan Professional Edition, Pix 4D Pro mapper.

The cameras used for the experiment are consumer, non-metric cameras and they have not been pre-calibrated. The field tests resulted in 3 blocks of images:

1. 84 images with a Panasonic DMC-FT1 camera - without geo-references.

2. 192 images with a Panasonic DMC-FZ30 camera - without geo-references.

3. 256 images with an FC350 from DJI Inspire 1 - with geo-references.

Each of the blocks was processed four times in order to generate a 3D model of the test building and to compare the use of the selected image acquisition method, the 3D software and the computer unit. A single process of generating a 3D model in Agisoft or Pix4D software consists of 4 steps:

Step 1 - adding a block of images to the project (align photo) - images can be added one-by-one or in groups. For non- geo-referenced images it is extremely important to enter them in the right order, because the image processing is done sequentially, with successive stereograms, which are subsequently joined in blocks which, in turn, are further processed. Moreover, this step involves the acquisition of metadata contained in EXIF data of the images being processed, particularly data on the focal length of the camera and the geographical coordinates of the principal point of an image. The data acquired will be used to generate the camera calibration metrics, which will help to obtain the approximate parameters of the external image orientation. Geo-tagged images can be aligned freely, interlinking the images to make a uniform block without localisation in space (generic) and geo-referenced in a selected frame of reference (e.g. PUWG 2000).

Step 2 - building a dense cloud.

Step 3 - building mesh - the software generates a 3D mesh which makes an object surface on a dense cloud. The mesh is generated by the algorithmic creation of a 3D mesh. The applications analysed here can be used for the basic editing of the mesh, e.g. deleting detached elements or closing gaps in the mesh.

Step 4 - building the texture of a building - selecting the mode of applying the texture optimises the method of its storage in the texture atlas, which improves the final quality of the model visualisation. 
When evaluating the quality of the generated models, such parameters should be compared as: the number of alignment points, the number of points in the dense cloud and the number of generated polygons. The models created in the experiment were similar in terms of the number of alignment points and the number of polygons; significant differences were observed only for the dense cloud. Table 1 presents a comparison of the parameters for all generated models. The parameters are affected mainly by the selected processing options; modelling was done with default settings in both programs. The tests showed that the performance of the graphic workstation used in the experiment does not affect the model quality.

Table 1. The number of points in a dense cloud of 3D models generated in Agisoft and Pix4D software

\begin{tabular}{|l|c|c|}
\hline Camera Software & Agisoft & Pix4D \\
\hline FT1 & & \\
\hline FZ30 & 5792999 & 4696298 \\
\hline Inspire1 & 6213555 & 6134285 \\
\hline FT1+Inspire1 & 8612709 & 10079726 \\
\hline
\end{tabular}

This table clearly shows that the number of generated points does not depend on the software used. Depending on the camera used, the number of generated points was greater in some instances by Agisoft software, while in others by Pix4D. The processing parameters were not changed in either of the programs. Despite the number of points, which reached nearly $30 \%$ in some cases, the visual assessment found no significant differences in the quality of the final model. The times needed for the successive stages of transforming a block of images into a 3D model are presented in table 2 .

The analysis showed that the difference in the number of steps arises from combining two processes in step 3 in the Pix4D software: generating a mesh of triangles and generating the texture of the object being modelled. In order to be able to compare the labour intensity of different steps in both Agisoft programmes, the processing times for steps 3 and 4 were summed and the result is presented in chart 1. 
Table 2. Processing times of successive steps of creation of a 3D model in the tested software (default settings)

\begin{tabular}{|c|c|c|c|c|c|c|c|c|c|c|}
\hline \multirow[t]{2}{*}{ No } & \multicolumn{2}{|c|}{ Image processing stage } & Duration & $\begin{array}{c}\text { Accrued } \\
\text { time }\end{array}$ & Duration & $\begin{array}{c}\text { Accrued } \\
\text { time }\end{array}$ & Duration & $\begin{array}{c}\text { Accrued } \\
\text { time }\end{array}$ & Duration & $\begin{array}{c}\text { Accrued } \\
\text { time }\end{array}$ \\
\hline & Agisoft & Pix4D & \multicolumn{2}{|c|}{$\begin{array}{c}\text { Agisoft } \\
\text { Graphic workstation } \\
1\end{array}$} & \multicolumn{2}{|c|}{$\begin{array}{c}\text { Pix4D } \\
\text { Graphic workstation } \\
1\end{array}$} & \multicolumn{2}{|c|}{$\begin{array}{c}\text { Agisoft } \\
\text { Graphic workstation } \\
2\end{array}$} & \multicolumn{2}{|c|}{$\begin{array}{c}\text { Pix4D } \\
\text { Graphic workstation } \\
2\end{array}$} \\
\hline & & \multicolumn{9}{|c|}{$\begin{array}{ll} & \text { Panasonic DMC-FT1 } \\
\end{array}$} \\
\hline 1 & \begin{tabular}{|l|} 
Align \\
Photos
\end{tabular} & $\begin{array}{l}\text { Local } \\
\text { Processing }\end{array}$ & Oh $14 \mathrm{~m}$ & & Oh $11 \mathrm{~m}$ & & Oh 6m & & Oh $8 \mathrm{~m}$ & \\
\hline 2 & $\begin{array}{l}\text { Build } \\
\text { Dense } \\
\text { Cloud }\end{array}$ & $\begin{array}{l}\text { Point Cloud } \\
\text { Densification }\end{array}$ & Oh $8 \mathrm{~m}$ & Oh $22 \mathrm{~m}$ & Oh $5 \mathrm{~m}$ & Oh $16 \mathrm{~m}$ & Oh $6 \mathrm{~m}$ & Oh $12 \mathrm{~m}$ & Oh $6 \mathrm{~m}$ & Oh $14 \mathrm{~m}$ \\
\hline 3 & $\begin{array}{l}\text { Build } \\
\text { Mesh }\end{array}$ & \multirow{2}{*}{$\begin{array}{l}\text { Generate 3D } \\
\text { Textured Mesh }\end{array}$} & Oh $6 \mathrm{~m}$ & Oh $28 \mathrm{~m}$ & \multirow{2}{*}{ Oh $1 \mathrm{~m}$} & \multirow{2}{*}{ Oh $17 \mathrm{~m}$} & Oh $6 \mathrm{~m}$ & Oh $18 \mathrm{~m}$ & \multirow{2}{*}{ Oh $2 \mathrm{~m}$} & \multirow{2}{*}{ Oh $16 \mathrm{~m}$} \\
\hline 4 & \begin{tabular}{|l} 
Build \\
Texture
\end{tabular} & & Oh 1m & Oh 29m & & & Oh 1m & Oh 19m & & \\
\hline & & \multicolumn{9}{|c|}{ Panasonic DMC-FZ30 } \\
\hline 1 & $\begin{array}{l}\text { Align } \\
\text { Photos }\end{array}$ & $\begin{array}{l}\text { Local } \\
\text { Processing }\end{array}$ & $1 \mathrm{~h} \mathrm{3m}$ & & Oh 29m & & Oh 23m & & Oh 23m & \\
\hline 2 & $\begin{array}{l}\text { Build } \\
\text { Dense } \\
\text { Cloud }\end{array}$ & $\begin{array}{l}\text { Point Cloud } \\
\text { Densification }\end{array}$ & Oh $5 \mathrm{~m}$ & $1 \mathrm{~h} 8 \mathrm{~m}$ & Oh $21 \mathrm{~m}$ & Oh $50 \mathrm{~m}$ & Oh $4 \mathrm{~m}$ & Oh $27 \mathrm{~m}$ & Oh 10m & Oh $33 \mathrm{~m}$ \\
\hline 3 & $\begin{array}{l}\text { Build } \\
\text { Mesh }\end{array}$ & \multirow{2}{*}{$\begin{array}{l}\text { Generate 3D } \\
\text { Textured Mesh }\end{array}$} & Oh 5m & $1 \mathrm{~h} 13 \mathrm{~m}$ & \multirow{2}{*}{ Oh $3 \mathrm{~m}$} & \multirow{2}{*}{ Oh $53 \mathrm{~m}$} & Oh 5m & Oh 32m & \multirow{2}{*}{ Oh $3 \mathrm{~m}$} & \multirow{2}{*}{ Oh $36 \mathrm{~m}$} \\
\hline 4 & \begin{tabular}{|l} 
Build \\
Texture \\
\end{tabular} & & Oh $2 m$ & $1 \mathrm{~h} \mathrm{15m}$ & & & Oh 1m & Oh 33m & & \\
\hline & & \multicolumn{9}{|c|}{ DJI Inspire1 } \\
\hline 1 & \begin{tabular}{|l|} 
Align \\
Photos \\
\end{tabular} & $\begin{array}{l}\text { Local } \\
\text { Processing }\end{array}$ & $1 \mathrm{~h} \mathrm{59m}$ & & Oh 45m & & Oh 43m & & Oh 33m & \\
\hline 2 & $\begin{array}{l}\text { Build } \\
\text { Dense } \\
\text { Cloud }\end{array}$ & $\begin{array}{l}\text { Point Cloud } \\
\text { Densification }\end{array}$ & $1 \mathrm{~h} \mathrm{0m}$ & $2 \mathrm{~h} 59 \mathrm{~m}$ & $1 \mathrm{~h} 3 \mathrm{~m}$ & 1h 48m & Oh 33m & $1 \mathrm{~h} \mathrm{16m}$ & Oh $26 \mathrm{~m}$ & Oh $59 \mathrm{~m}$ \\
\hline 3 & $\begin{array}{l}\text { Build } \\
\text { Mesh }\end{array}$ & \multirow{2}{*}{$\begin{array}{l}\text { Generate 3D } \\
\text { Textured Mesh }\end{array}$} & Oh 6m & $3 \mathrm{~h} 5 \mathrm{~m}$ & \multirow{2}{*}{ Oh $5 \mathrm{~m}$} & \multirow{2}{*}{$1 \mathrm{~h} 53 \mathrm{~m}$} & Oh 6m & $1 \mathrm{~h} 22 \mathrm{~m}$ & \multirow{2}{*}{$0 h 6 m$} & \multirow{2}{*}{$1 \mathrm{~h} 5 \mathrm{~m}$} \\
\hline 4 & \begin{tabular}{|l|} 
Build \\
Texture \\
\end{tabular} & & Oh $2 \mathrm{~m}$ & $3 \mathrm{~h} \mathrm{7m}$ & & & Oh 3m & 1h 25m & & \\
\hline & & \multicolumn{9}{|c|}{ Panasonic DMC-FT1 + DJI Inspire1 } \\
\hline 1 & \begin{tabular}{|l|} 
Align \\
Photos
\end{tabular} & $\begin{array}{l}\text { Local } \\
\text { Processing }\end{array}$ & 3h $27 \mathrm{~m}$ & & $1 \mathrm{~h} 4 \mathrm{~m}$ & & 1h 16m & & Oh $48 \mathrm{~m}$ & \\
\hline 2 & $\begin{array}{l}\text { Build } \\
\text { Dense } \\
\text { Cloud } \\
\end{array}$ & $\begin{array}{l}\text { Point Cloud } \\
\text { Densification }\end{array}$ & $1 \mathrm{~h} 0 \mathrm{~m}$ & 4h $27 \mathrm{~m}$ & $1 \mathrm{~h} 41 \mathrm{~m}$ & $2 \mathrm{~h} 45 \mathrm{~m}$ & Oh $35 \mathrm{~m}$ & $1 \mathrm{~h} 51 \mathrm{~m}$ & Oh $37 \mathrm{~m}$ & 1h $25 \mathrm{~m}$ \\
\hline 3 & $\begin{array}{l}\text { Build } \\
\text { Mesh }\end{array}$ & \multirow{2}{*}{$\begin{array}{l}\text { Generate 3D } \\
\text { Textured Mesh }\end{array}$} & Oh 6m & $4 \mathrm{~h} 33 \mathrm{~m}$ & \multirow[b]{2}{*}{ Oh $4 \mathrm{~m}$} & \multirow[b]{2}{*}{$2 \mathrm{~h} \mathrm{49m}$} & Oh $7 \mathrm{~m}$ & $1 \mathrm{~h} 58 \mathrm{~m}$ & \multirow[b]{2}{*}{ Oh $6 \mathrm{~m}$} & \multirow[b]{2}{*}{ 1h $31 \mathrm{~m}$} \\
\hline 4 & \begin{tabular}{|l|} 
Build \\
Texture \\
\end{tabular} & & Oh $3 \mathrm{~m}$ & $4 h 36 m$ & & & Oh $2 \mathrm{~m}$ & $2 \mathrm{~h} \mathrm{0m}$ & & \\
\hline
\end{tabular}

An analysis of the test results indicates that the automated processes are more effectively and quickly carried out by the Pix4D software. For example, a comparison of the time needed by both applications during the first step of processing a block of images acquired by an unmanned aerial vehicle marked on the diagram as [11], Align Photos shows that Agisoft needed 119 minutes to complete the process on graphic workstation no. 1 and 43 minutes on graphic workstation no. 2, whereas Pix4D carried out this step in 45 and 33 minutes, respectively.

Examples of images taken for this experiment and the images rendered during the process of generating a 3D model with the Agisoft and Pix4D software are presented below (Fig. 1-3). 


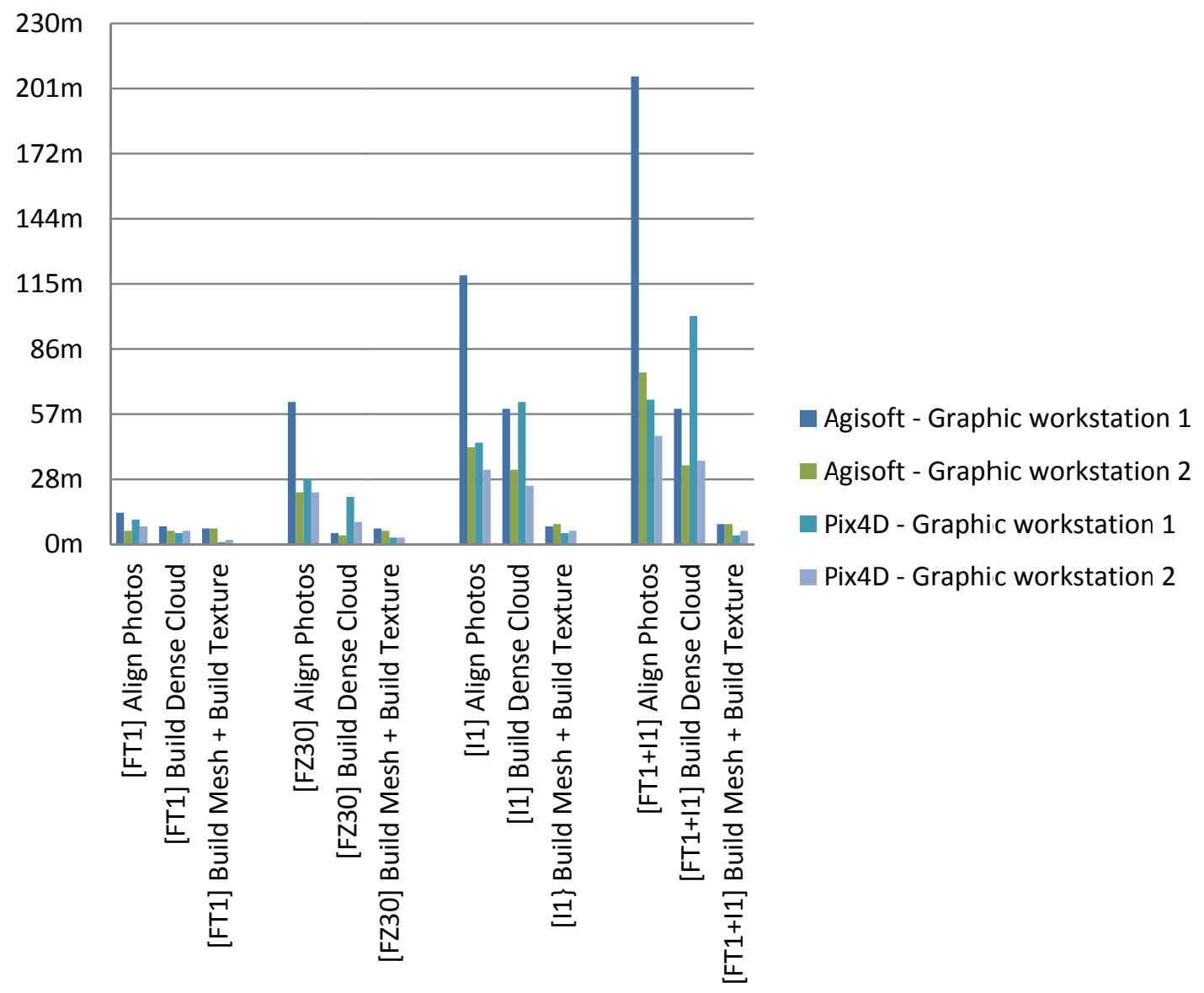

Chart 1. Times of processing of different blocks of images, broken down into stages, software and graphic workstations

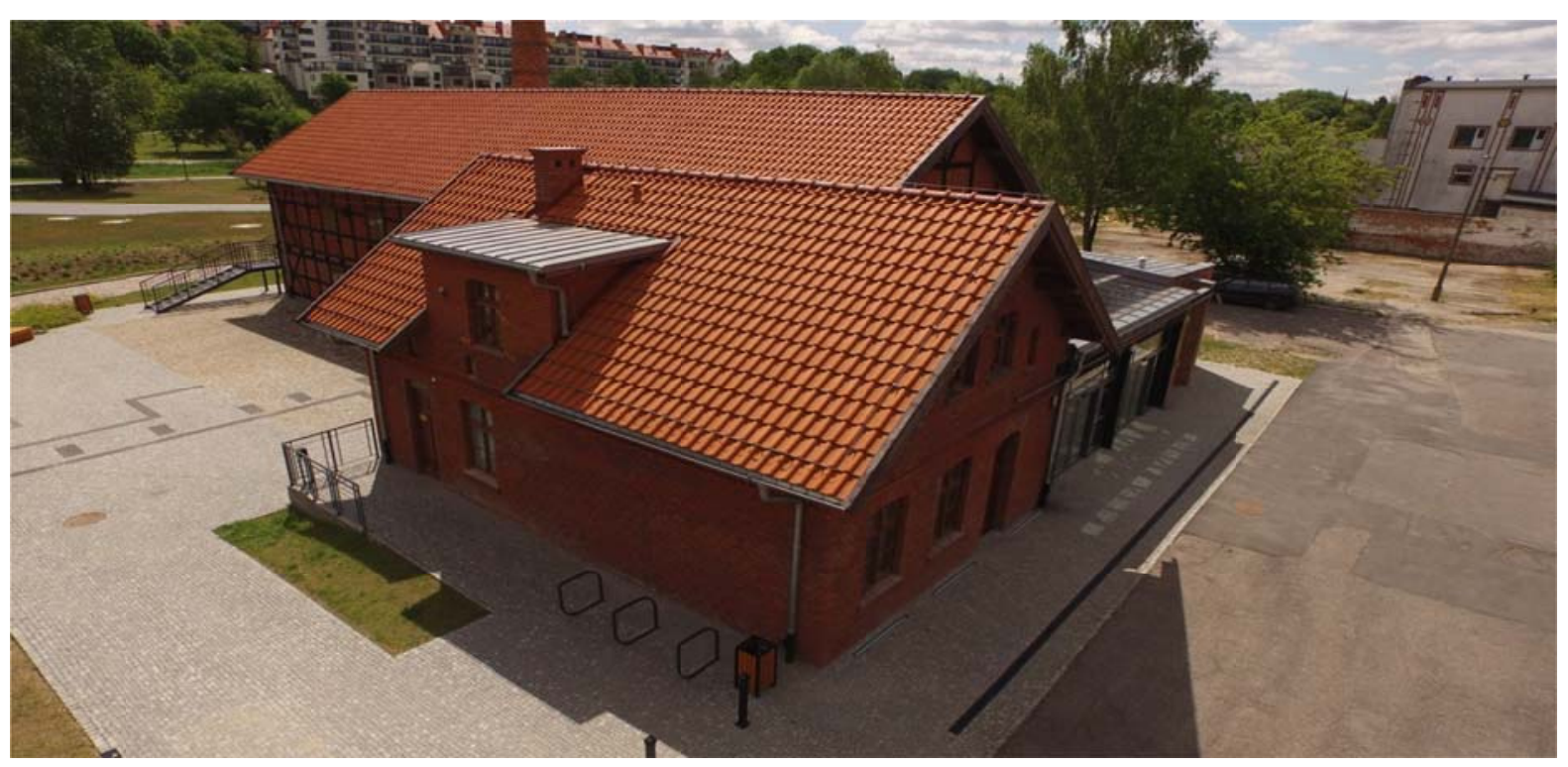

Fig. 1. A geo-referenced image taken with a non-metric digital camera FC350 from a quadrocopter - DJI Ispire 1 (resolution 12 Mpix) 


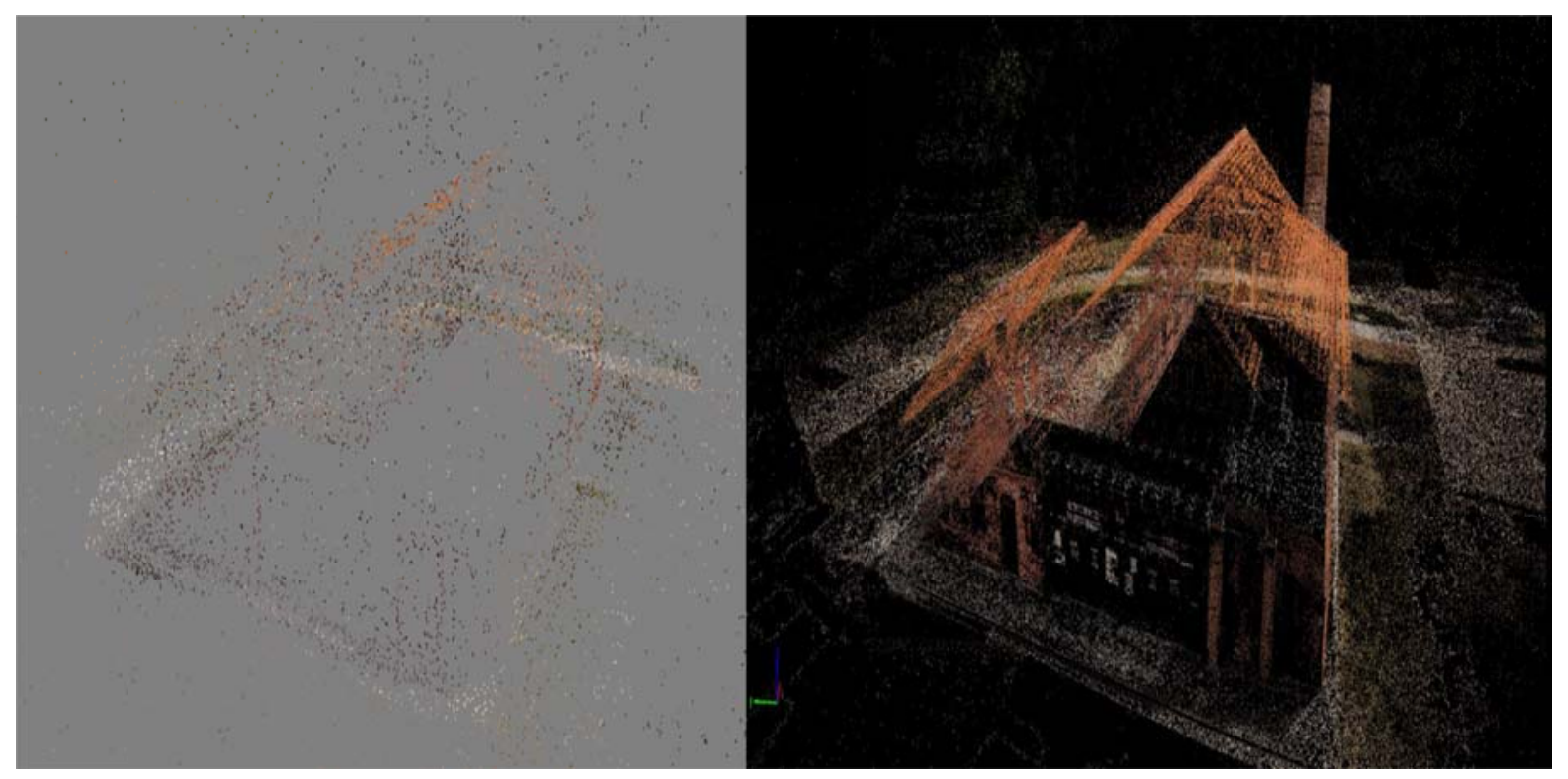

Fig. 2. Image (Points Cloud) generated by the tested software: on the left - Agisoft Photo Scan Professional Edition, on the right - Pix4D Pro mapper

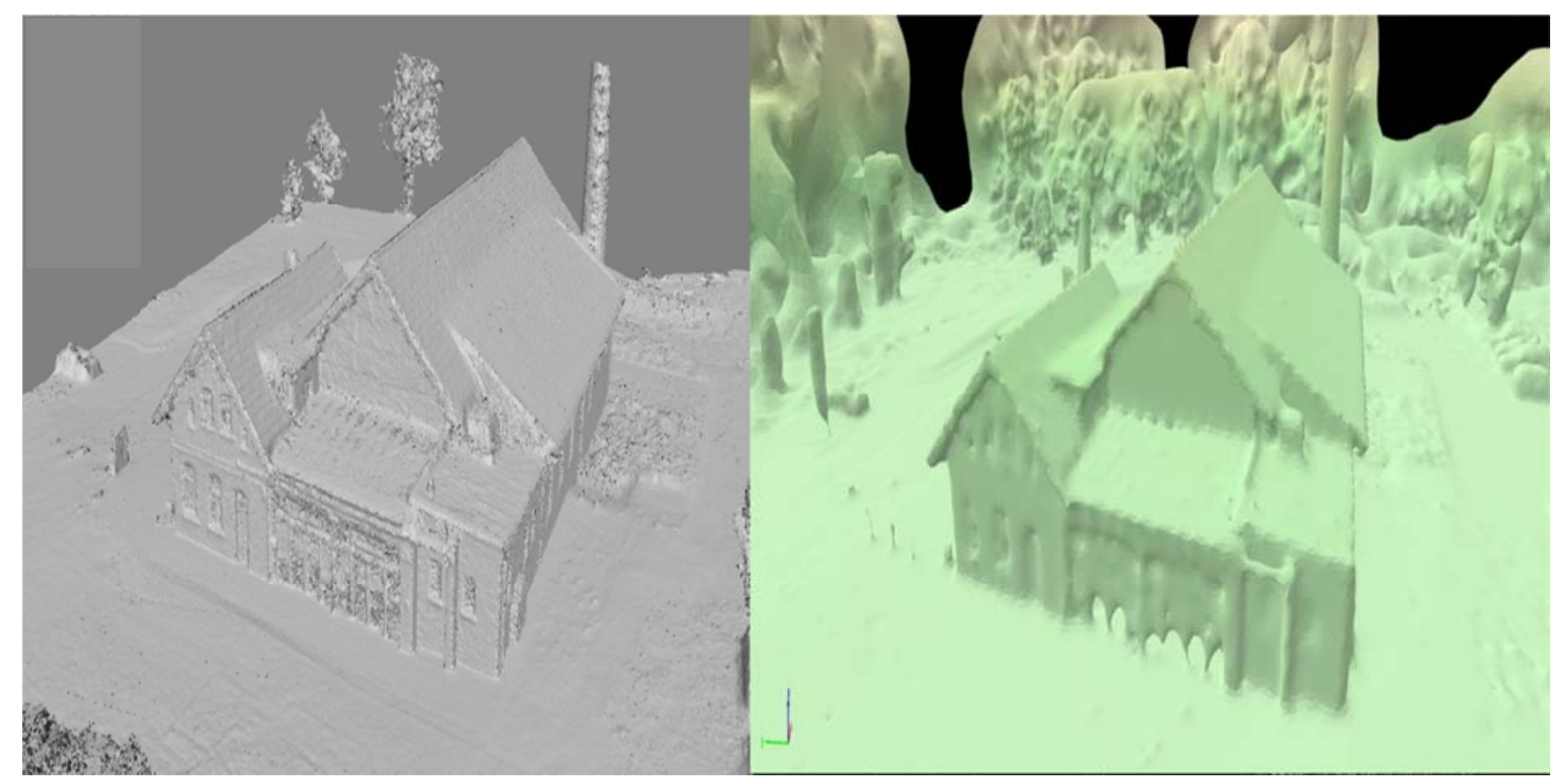

Fig. 3. Image (Dense Cloud) generated by the tested software: on the left - Agisoft Photo Scan Professional Edition, on the right - Pix4D Pro mapper 


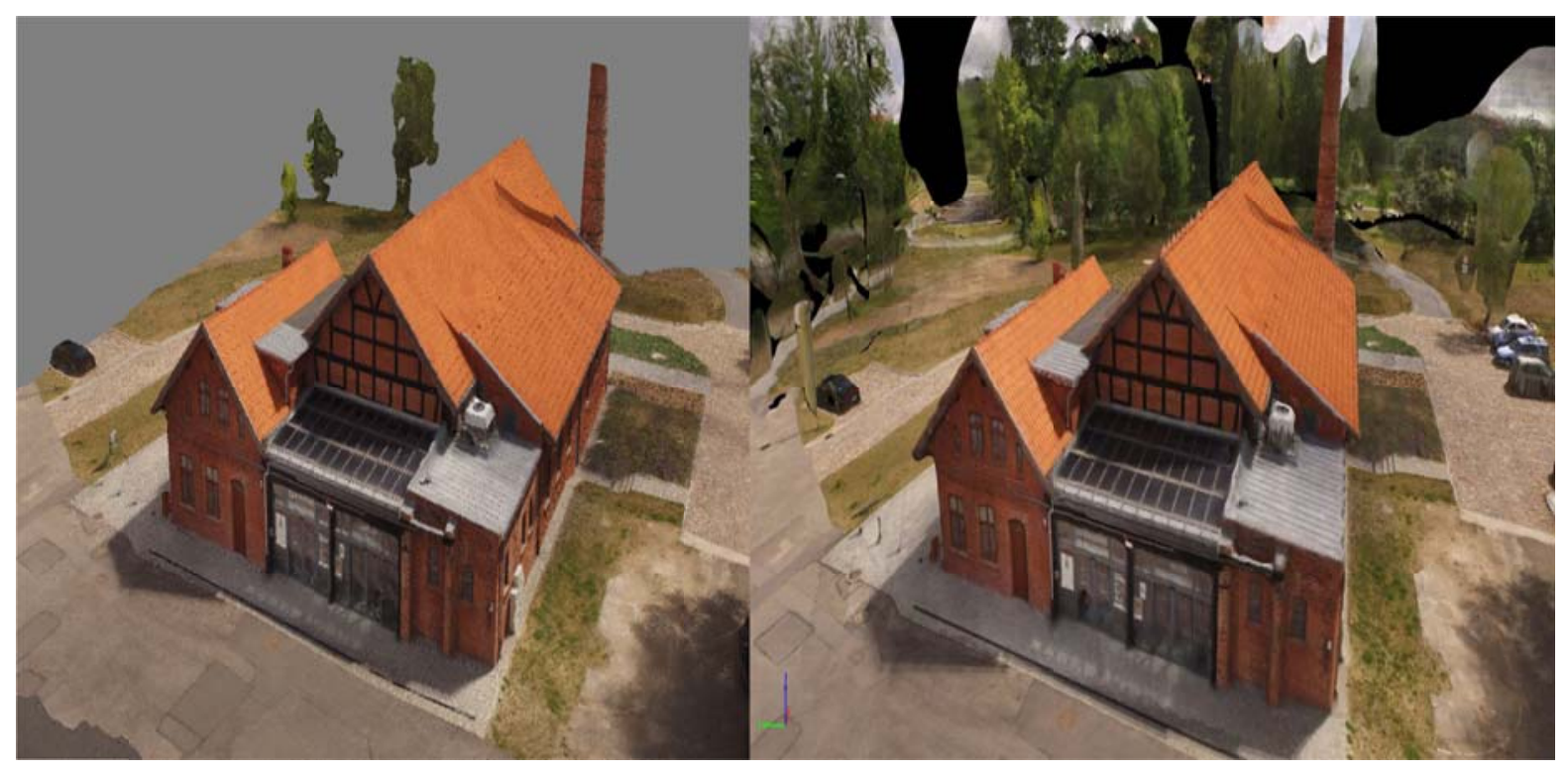

Fig. 4. Image (Texture) generated by the tested software:

(on the left - Agisoft Photo Scan Professional Edition, on the right - Pix4D Pro mapper

\section{Conclusions}

The following conclusions can be drawn from this experiment:

1. In order to increase the precision of the generated model, the following points are needed:

1.1. To develop a plan of flight which takes into account the features of the building whose model is generated;

1.2. The flight must be done in the right lighting and weather conditions:

- the sun at the zenith (this minimises the length of the shadow and the size of the shaded area of the building);

- slightly cloudy weather (reduces the tonal range of the images, prevents formations of sharp transitions between brightly lit and shaded areas);

- no precipitation (in principle, unmanned aerial vehicles are not suited to flying when it is raining; rain drops can contaminate the camera objective, making patches visible in images);

- no wind (strong wind or gusts hinder precision flight, both in manual control mode and in an autonomous flight);

1.3. Properly select the model of the unmanned aerial vehicle and the type of camera;

1.4. Calibrate the camera;

1.5. Use signalled photopoints;

1.6. Select processing parameters properly;

1.7. Generate a model in a supervised process.

2. The camera should have:

- calibration data;

- an RGB sensor with a wide angle and small barrel distortion;

- a resolution of at least 12 Mpix;

- manual settings; 
- controllability within the range from 90 to 180 degrees (from the objective directed forwards to the objective directed vertically downwards).

3. To increase the geometric and radiometric quality of the 3D model:

- generating a full 3D model of the building structure is not possible only from blocks of ground-based photographs;

- increasing the number of photographs does not directly improve the quality of the model, but it increases the amount of time needed to process it;

- the model quality is directly affected by selected processing parameters;

- the quality of a 3D model generated automatically, in a non-supervised process, is sufficient for model applications, e.g. for creating 3D animations or for making spatial analyses (e.g. insolation analyses);

- the quality of the models generated in both programmes is similar and the differences stem from slight differences in default settings.

The experiments and analyses have shown that when certain parameters established in an experiment are followed, such as the type of an unmanned aerial vehicle and the navigation software, digital camera and methods of its calibration, the principles of designing and performing the flight and properly selecting the data processing software, the process of developing the stock-taking documentation for a historical building moves from the standards of analogue to digital technology with considerably reduced cost. This process can also be used to develop technical guidelines to prepare stock-taking documentation for a historical building.

\section{References}

Boroń, A., Borowiec, M., \& Wróbel, A. (2009). Rozwój cyfrowej technologii w inwentaryzacji obiektów zabytkowych na przykładzie doświadczeń Zakładu Fotogrametrii i Informatyki Teledetekcyjnej AGH. Archiwum Fotogrametrii, Kartografii i Teledetekcji, 19, 11-22.

Bruno, F., Bruno, S., De Sensi, G., Luchi, M. L., Mancuso, S., \& Muzzupappa, M. (2010). From 3D reconstruction to virtual reality: A complete methodology for digital archaeological exhibition. Journal of Cultural Heritage, 11(1), 42-49.

Brumana, R., Oreni, D., Alba, M., Barazzetti, L., Cuca, B., \& Scaioni, M. (2012). Panoramic UAV Views for Landscape Heritage Analysis Integrated with Historical Maps Atlases. Geoinformatics FCE CTU, 9, 39-50.

Bykov, A., Kostiuk, A., Bykov, V., Bykov, L., Tataurova L., Orlov P., \& Pogarsky, P. (2014). Geodetic support archeological work using UAV and methods stereophotogrammetry. InterEkspo Geo-Sybir, 1(4), 1-6.

Diara, F. (2013). New software and technologies applied to documentation and communication of Cultural Heritage. Proceedings of the 18th International Conference on Cultural Heritage and New Technologies 2013 (CHNT 18, 2013) from http://www.chnt.at/proceedings-chnt-18/ 
Hirschmuller, H. (2008). Stereo processing by semi-global matching and mutual information. IEEE Transactions on Pattern Analysis and Machine Intelligence, 30, 328-341.doi:10.1109/TPAMI.2007.1166

Koch, R., Pollefeys, M., \& Van Gool, L. (1998). Automatic 3D Model Acquisition from Uncalibrated Image Sequences. Computer Graphics International, Proceedings, 597-604. doi:10.1109/CGI.1998.694318

Pierrot-Deseilligny, M., De Luca, L., \& Remondino, F. (2011). Automated imagebased procedures for accurate artifacts 3D modeling and orthoimage generation. Geoinformatics FCE CTU, 6, 291-299. doi:http://dx.doi.org/10.14311/gi.6.36

Pollefeys, M., Koch, R., Vergauwen, M., \& Van Gool, L. (1999). Hand-held acquisition of 3D models with a video camera. 3-D Digital Imaging and Modeling, Proceedings, 14-23. doi:10.1109/IM.1999.805330

Preuss, R. (2014). Automation of image data processing. Archiwum Fotogrametrii, Kartografii i Teledetekcji, 26, 119-127. doi:10.14681/afkit.2014.010

Pueschel, H., Sauerbier, M., \& Eisenbeiss, H. (2008). A 3D model of Castle Landenberg $(\mathrm{CH})$ from combined photogrammetric processing of terrestrial and UAV-based images. The International Archives of the Photogrammetry, Remote Sensing and Spatial Information Sciences, Vol. XXXVII, 93-98.

Remondino, F. (2011). Digital 3D recording for heritage documentation and preservation - latest developments and perspectives. In M. Fioravanti, S. Mecca (Ed.), The Safeguard of Cultural Heritage: A Challenge From the Past for the Europe of Tomorrow: COST strategic workshop (pp. 261-264). Firenze: Firenze University Press.

Sauerbier, M., \& H. Eisenbeiss, H. (2010). UAVS for the documentation of archaeological excavations. International Archives of Photogrammetry, Remote Sensing and Spatial Information Sciences, Vol. XXXVIII, 526-531.

Uysal. M., Toprak, \& A.S., Polat, N. (2013). Photo realistic 3D modeling with UAV: Gedik Ahmet Pasha Mosque in Afyonkarahisar. International Archives of the Photogrammetry, Remote Sensing and Spatial Information Sciences, XL-5/W2, 659-662.

\section{Authors:}

Aleksander Zarnowski ${ }^{1)}$, Ph.D., Professor, azarnowski@wilsig.tu.koszalin.pl Anna Banaszek ${ }^{2}$, Ph.D., Assistant Professor, anna.banaszek@uwm.edu.pl Sebastian Banaszek ${ }^{3)}$, Ph.D., Director of Operations, Licensed Unmanned Aerial Vehicles Operator, sebastian.banaszek@dronhouse.pl

1) Department of Geoinformatics, Koszalin University of Technology, Koszalin, Poland, Śniadeckich 2, 75-453, Koszalin, Poland

2) University of Warmia and Mazury, Faculty of Geodesy, Geospatial and Civil

Engineering, Department of Real Estate Resources, Prawocheńskiego 15, 10-724, Olsztyn, Poland

3) Dron House S. A., Twarda 18, 00-105, Warszawa, Poland 